\title{
SOBRE LA TRADUCCIÓN FRASEOLÓGICA
}

\author{
LARISSA TIMOFEEVA \\ Universidad de Alicante \\ Timofeeva@ua.es
}

\begin{abstract}
Resumen
En este artículo presentamos un panorama general de la problemática de la traducción de los fraseologismos. La tradicional complejidad asociada a este ámbito traductológico deriva de la propia naturaleza de la significación fraseológica. Por ello, cualquier acercamiento interlingüístico a la fraseología ha de partir de una reflexión previa en torno a cómo las unidades fraseológicas (UF) realizan su función significativa. Como mostramos en este trabajo, los enfoques adoptados en este ámbito hasta ahora no indagan en toda la gama de aspectos que despliega la UF en su comportamiento comunicativo, por lo que la traductología fraseológica muestra la necesidad de una profunda reformulación de sus métodos. Dicha reformulación ha de adoptar, a nuestro juicio, el marco de la pragmática con el fin de dar cuenta del comportamiento fraseológico, tanto en el nivel del significado convencionalizado como el discursivo.
\end{abstract}

PALABRAS CLAVE: fraseología, traducción.

\begin{abstract}
This article offers a panoramic review of the translation concerning idioms. The complexity traditionally associated with this field emerges from the nature of the phraseological meaning itself. For this reason, a crosslinguistic approach to phraseology should depart from the previous question about how phraseological units develop their meaning function. As will be shown, the traditional, functional approaches do not analyze the whole range of aspects defining the phraseological communicative behavior. Thus, translation concerning idioms requires reformulating its methodology. The pragmatic approach becomes the most suitable perspective for the analysis of phraseological meaning on both semantic and discursive level.
\end{abstract}

KEY WORDS: phraseology, translation.

\section{Introducción}

Cuando hablamos de la traducción, hablamos de, tal vez, uno de los más antiguos oficios del hombre. Es lógico pensar que los primeros actos de traducción se fechan en el mismo momento en que los hombres de un lugar toman conciencia de que hablan una lengua distinta a la de los hombres de otro lugar. Y, por supuesto, el nacimiento de la escritura marca el inicio de la actividad traductora como una actividad profesional. Las obras monumentales de distintas culturas se ven envueltas en el proceso de trasla- 
ción de su contenido a otras lenguas, proceso que se ve como parte esencial de la conquista cultural una vez acabada la faena bélica.

Pese a tal antigüedad, la traducción no se convierte en objeto de estudio teórico hasta los primeros años del siglo pasado. De esta forma, estamos ante una disciplina de fuerte raigambre empírica, que ha ido construyendo y sistematizando su base teórica tras muchos siglos de práctica. Tal hecho se hace sentir hasta hoy, pues la traducción es una de esas disciplinas que acoge o "ejecuta" las propuestas que surgen en su seno en función de la aplicabilidad que tienen a la práctica traductológica real. Por ello, se requiere una profunda indagación previa con el fin de determinar la naturaleza de los problemas reales, inherentes a la traducción. Tal indagación se reviste de aun mayor importancia si hablamos de las parcelas traductológicas más específicas, donde la complejidad del objeto de la traducción deriva de sus propiedades idiosincrásicas, como es el caso de las unidades fraseológicas (UF).

A continuación, presentaremos una visión panorámica de la problemática de la traducción de los fraseologismos, con el objetivo de destacar los aspectos particulares que, a nuestro juicio, han de marcar el desarrollo de este ámbito en relación a la lingüística actual. De esta manera, en primer lugar hablaremos de la concepción tradicional de la traductología fraseológica, aún muy vigente en la actualidad. Seguidamente, analizaremos las propuestas de corte funcional que pretenden solucionar los problemas de la translación fraseológica desde una perspectiva más práctica, con atención a la función de las UF. Finalmente, las deficiencias detectadas en las concepciones anteriores nos llevan a plantear la idoneidad de una perspectiva de índole pragmática que permita dar cuenta de toda la complejidad del fenómeno de traducción fraseológica.

Los diversos estados teóricos que caracterizan la traductología fraseológica se exponen aquí a través de propuestas concretas, presentadas como reflexiones previas que pretenden mostrar el cuadro general de la disciplina. Cabe insistir en que las propuestas teóricas elegidas con fines ilustrativos, obviamente, no abarcan la totalidad de las aportaciones al tema' ${ }^{1}$, aunque sí nos parecen muy representativas y dan buena cuenta de la situación global del ámbito tratado.

\footnotetext{
${ }^{1}$ Naturalmente, muchos otros autores han tratado la problemática de la fraseología desde el punto de vista contrastivo centrando la atención en sus aspectos lingüísticos y antropológicos (cfr. Retsker (1950); Larreta Zulategui (2001); López Roig (2002); Almela et al. (eds.) (2005); González y Mogorrón (eds.) (2008); Dobrovol'skij y Piirainen (2005); Dobrovol'skij (en prensa), entre muchos otros).
} 


\section{La traductología fraseológica: estado de la cuestión}

La problemática a la que se enfrenta la traductología fraseológica en su concepción más tradicional se fundamenta en el tratamiento que se da en su interior a las UF. Ya se ha convertido en un lugar común hablar de las dificultades de traducción de los fraseologismos. Incluso, se ha llegado a afirmar la intraducibilidad de algunos de ellos, debido a las referencias históricas o socioculturales que encierran. En ocasiones, la propia actitud del traductor "ante lo que considera como más idiosincrásico y particular de la comunidad de origen, $\mathrm{y}$, por tanto, de difícil o imposible traducción a la comunidad meta" (Corpas, 2003: 213), puede impedir una traslación fluida de los contenidos fraseológicos de una lengua a otra.

Quiroga (2006: 2029-2030) distingue dos tipos de problemas ${ }^{2}$ a los que se enfrenta el traductor de las UF: los relativos a la naturaleza fraseológica y los relacionados con el proceso de traducción. Los de primer tipo se subdividen en cuatro categorías, en función del tipo de las UF comparadas, como se expone a continuación:

- expresiones que contienen una referencia específica a hechos, circunstancias o personajes exclusivos del marco histórico cultural de la lengua de partida;

- expresiones que presentan una correspondencia válida en otras lenguas;

- UF cuya base metafórica coincide en la lengua origen y la lengua meta;

- los falsos amigos fraseológicos.

Las dificultades relacionadas con el proceso de traducción se refieren a los problemas que pueden surgir en distintas fases del mismo, a saber, la de identificación de la UF, su adecuada interpretación y, finalmente, la búsqueda de equivalentes (Quiroga, 2006: 2030; cfr. también Corpas, 2003: 215-222). Las tres fases están estrechamente relacionadas, y los problemas en una de ellas arrastran dificultades en las otras. Dicho de otro modo, si una UF no está correctamente identificada, no puede ser adecuadamente interpretada, por lo que la búsqueda de equivalentes se agrava seriamente. Lógicamente, los problemas que pueda encontrar el traductor en cada una de las fases del proceso pueden estar relacionados con la naturaleza de las UF, esto es, con los de primer tipo.

\footnotetext{
${ }^{2}$ En este artículo utilizaremos los términos de problema y de dificultad indistintamente, sin dotarlos del significado específico que adquieren en la traductología a raíz de la distinción que establece Ch. Nord ([1988] 1991). Recordemos que para esta autora, un problema de traducción es inherente al texto, mientras que una dificultad se plantea en relación a la competencia del traductor.
} 
Al margen de que tal visión de la problemática de la traducción de las UF pueda parecer algo simplista, creemos importante señalar que es una buena muestra de la persistencia del marco descriptivo-clasificatorio - aunque con frecuencia convenientemente disfrazado de mayor "modernidad" - vigente en la traductología general. Como se observa, el objetivo consiste en establecer taxonomías de UF que determinen los problemas de su traducción y que influyan directamente, por tanto, en el proceso de la toma de decisiones.

Dicho proceso de la toma de decisiones se plasma en la búsqueda de equivalentes de las UF del texto origen en el texto meta, sin atender a todos los factores y condicionamientos que participan en la cofiguración del significado fraseológico completo. Cabe subrayar que, pese a que el procedimiento descrito ha sido duramente criticado en la teoría de traducción general, en la traductología fraseológica sigue ampliamente asumido. Y ello resulta más incomprensible si atendemos al hecho de que su aplicación, tanto a la práctica fraseográfica como a la traductológica, conlleva dificultades, que a veces resultan insalvables. Estos aspectos quedan reflejados en la concepción de equivalencia fraseológica que desarrollamos a continuación.

\subsection{La equivalencia fraseológica}

G. Corpas en varios de sus artículos dedicados a la problemática de la traducción de las UF (cfr. Corpas, 2000; así como diversos artículos de esta autora recopilados en Corpas, 2003, entre otros), señala que el proceso en cuestión sucede en tres grandes pasos o fases ${ }^{3}$, a saber, la fase de identificación, la fase de interpretación y la fase de búsqueda de correspondencias. La única novedad que presenta la propuesta de Corpas consiste en que las tres fases se enfocan con cierta independencia ${ }^{4}$, mientras que en la visión más tradicional solo la última de ellas era objeto de estudio más o menos sistemático. A continuación describiremos con más detalle las fases en cuestión siguiendo fundamentalmente a Corpas (2003).

\footnotetext{
${ }^{3}$ En realidad, como se desprende de la exposición de la problemática en Corpas (2003: 213-223), cabe hablar más bien de dos fases, pues la primera y la segunda prácticamente se solapan y complementan una a la otra.

${ }^{4} \mathrm{Tal}$ independencia no quiere decir, de ningún modo, que las tres fases del proceso de traducción de las UF se contemplen en autonomía unas de las otras, sino que el hecho de 'aislarlas' permite construir un acercamiento teórico más riguroso a los procesos implicados en cada una de ellas.
} 


\subsubsection{La fase de identificación y de interpretación}

Corpas destaca que el primer paso para traducir una UF consiste en identificarla correctamente, para, a continuación, dotarla de una interpretación adecuada al contexto dado. En otras palabras, el traductor debe evaluar el potencial de la UF, para contrastarlo con el funcionamiento de hecho dentro de un contexto particular, en el que la construcción despliega un abanico de informaciones semánticas, discursivas y funcionales válidas solo para las circunstancias concretas.

La tarea de identificación está ligada a una serie de dificultades. Como subraya Corpas (2003: 215-216), pese a que las características sistémicas de las propias UF, a saber, su fijación e idiomaticidad, proporcionan 'pistas' al traductor, no siempre las irregularidades están a la vista y son evidentes. Por ejemplo, en los casos en que la UF tiene un homófono literal, a veces la frontera entre la lectura literal y la fraseológica se hace muy tenue en el discurso. Ello suele obedecer a diversas intenciones comunicativas del hablante que pretende causar con tal procedimiento determinado efecto discursivo (v.g. la ironía) $)^{5}$. En estos casos, en efecto, el problema ya no es tanto la determinación de la UF en sí (i.e. su 'aislamiento' del resto del enunciado), sino la identificación de la actitud comunicativa del hablante. Estos aspectos se entrecruzan y constituyen una de las pruebas de la insuficiencia del marco teórico propuesto para el tratamiento de tales hechos.

En la concepción de Corpas parece que el proceso de identificación de la UF se solapa a menudo con el de interpretación, o, mejor dicho, ésta acompaña a aquella. Según entendemos nosotros el razonamiento de la autora ${ }^{6}$, la relación entre ambos procesos puede definirse del siguiente modo:

- en términos de práctica simultaneidad, cuando el traductor conoce muy bien el significado de la UF y su identificación deriva en una inmediata y adecuada interpretación semántico-discursiva;

- en términos de la anterioridad de la interpretación a la identificación, esto es, cuando, como en el caso de homófonos, la interpretación ayuda a identificar la UF;

\footnotetext{
${ }^{5}$ Estrictamente hablando, estos casos obedecerían a lo que en Timofeeva (2009a) tratábamos como desautomatización semántica. En este mismo trabajo, así como en Timofeeva (2009b), analizamos también algunos efectos pragmáticos producidos por este procedimiento discursivo.

${ }^{6}$ Aunque Corpas (2003: 216) dice explícitamente que la fase de interpretación es posterior a la de identificación, no parece desprenderse lo mismo de la descripción que hace la autora del proceso en la que, ciertamente, ambas fases van unidas.
} 
- en términos de posterioridad, cuando ante el desconocimiento del significado de la UF el traductor, aunque la identifique correctamente, debe recurrir a materiales de apoyo, como diccionarios, para proseguir con una interpretación adecuada.

No obstante, creemos que en la serie presentada falta la descripción de los casos en los que la fase de identificación simplemente se omite. En otras palabras, opinamos que en el discurso se dan con cierta frecuencia las situaciones en las que una UF se ve por el traductor como parte de toda la secuencia discursiva a la par con otros componentes, y ni siquiera se plantea su identificación. Pensamos que es el caso de algunas colocaciones y unidades sintagmáticas bien conocidas (especialmente si su traducción a la lengua meta se realiza en un solo lexema), así como de determinadas fórmulas rutinarias. A nuestro juicio, dichos casos se contemplan por el traductor como parte de su concepción de las lenguas implicadas en el proceso (i.e. su estructura, su tipología sintáctica, etc.); y de igual modo que el uso de un tiempo verbal compuesto, como el pretérito perfecto en español, no presupone la fase de identificación de tal forma compuesta con el objetivo de una interpretación adecuada, algunas estructuras fraseológicas, en virtud de su frecuencia del uso, han perdido para el traductor (y para el hablante en general) su especificidad interpretativa. Estas reflexiones tienen, naturalmente, un carácter hipotético, pero de ser ciertas, sería interesante observar cómo repercuten en la tercera fase del proceso de traducción, la fase de búsqueda de correspondencias.

\subsubsection{La fase de búsqueda de correspondencias}

Para Corpas, esta última fase de la traducción de UF está compuesta por dos subfases. Como señala la autora (Corpas, 2003: 216):

Tras las fases de identificación y posterior interpretación, el traductor procede al establecimiento de correspondencias, primero en el nivel lexicológico, el plano teórico, para, a continuación, bajar a los niveles textual y discursivo, en una palabra, al plano real.

De entrada, resulta sumamente acertada la concepción del proceso de búsqueda de correspondencias en al menos dos niveles, el semántico y el discursivo. Sin embargo, a nuestro juicio, el marco teórico que sigue la autora no le ha permitido explotar todo el potencial de tal concepción. A continuación expondremos sucintamente los contenidos que definen ambos planos. 


\subsubsection{El plano léxico}

En el primer nivel, el del plano léxico, se trata de encontrar un equivalente semántico a la UF del original. En este sentido, Corpas distingue tres grados de equivalencia, cada uno de los cuales requiere distintos procedimientos traductológicos (cfr. Corpas, 1997; 2000; 2003: passim)7. Veamos dichos grados en aplicación a las locuciones.

En primer lugar, se postula la existencia de una equivalencia total. En palabras de Corpas (2003: 206)

Dos locuciones presentan relación de equivalencia total cuando ambas forman un traslema ${ }^{8}$ en todo momento, es decir, cuando ambas se traducen mutuamente mediante la técnica de transferencia denominada sustitución.

Se trata de equivalentes fraseológicos que presentan el mismo significado denotativo y connotativo que se da en los mismos niveles diasistémicos (i.e. diastrático, diafásico, etc.). La equivalencia total es frecuente especialmente en denominaciones científicas, técnicas, etc., aunque también se da entre las locuciones propiamente dichas. En la mayoría de los casos las raíces de tal identidad hay que buscarlas en los orígenes comunes y en los procesos de prestación del léxico extranjero.

En segundo lugar, se habla de la equivalencia parcial, que se refiere, en palabras de Corpas (2003: 207), a los casos

cuando una locución de la L[engua] $\mathrm{O}$ [rigen] se traduce por una locución en la $\mathrm{L}$ [engua] $\mathrm{M}$ [eta] que presenta diferencias de significado denotativo o connotativo, o que pertenece a una variedad (diastrática, diafásica y diatópica) distinta; o es traducida por una unidad léxica simple carente de los valores expresivos de la locución en cuestión.

Como señala Corpas, pese a las diferencias señaladas, la locución original y la traducida forman un traslema por presentar el mismo valor funcional. Por lo tanto, comunicativamente son equivalentes, aunque deben compensarse a través del contexto. De no ser así, pueden darse situaciones de infratraducción o de sobretraducción. La primera de

\footnotetext{
${ }^{7}$ La formulación de la equivalencia fraseológica en términos de una escala gradual - que va de la equivalencia total a la equivalencia nula pasando por la equivalencia parcial - se retrotrae a las propuestas ya clásicas como la de Solodukho (1977) o de Raikhshtein (1980), aunque todas ellas responden al patrón comparativo general avanzado por Retsker (1950).

${ }^{8}$ Corpas sigue la propuesta terminológica de Santoyo y Rabadán (1991), según los que un traslema es "unidad bitextual de cualquier tipo o nivel constituida por un mismo contenido y dos manifestaciones formales diferenciadas pero solidarias y cuya existencia depende de la relación global de equivalencia subyacente a cada binomio textual T[exto]O[rigen]-T[exto]M[eta]" (Santoyo y Rabadán, 1991: 322 apud Corpas, 2003: 205).
} 
ellas se refiere a la falta en el texto meta de ciertos aspectos semánticos, estilísticos y otros presentes en el texto origen. La segunda, por el contrario, alude a los casos cuando la traducción recoge aspectos adicionales, no presentes en el texto ni, concretamente, en la locución original. Corpas (2003: 207-208) defiende que las diferencias que sustentan la equivalencia parcial se deben, fundamentalmente, a las diferencias de imágenes subyacentes o a distintos significados denotativos y connotativos. Como veremos más abajo, el hecho de tomar en consideración tales aspectos ha supuesto la reformulación de la noción de equivalencia fraseológica, coherente, además, con el marco traductológico general de corte funcional.

Finalmente, en tercer lugar, situamos los casos de equivalencia nula, es decir, aquellas UF del original que no presentan equivalentes de traducción en la lengua meta. En estos casos, el traductor se ve obligado a recurrir a la paráfrasis o a otras técnicas de transferencia, por lo que resulta imposible conservar los valores connotativos correspondientes.

Un caso aparte, tratado en ocasiones como un cuarto tipo de equivalencia, constituye el llamado fenómeno de "los falsos amigos". Se trata de casos cuando la UF en la lengua de origen y la UF en la lengua meta aparentan similitud formal en cuanto a sus componentes, pero difieren en el significado. Por ello, este fenómeno aparece también bajo el rótulo de equivalencia aparente, aunque estrictamente hablando no se trata de equivalencia, sino más bien de la mera coincidencia formal.

\subsubsection{El plano textual}

El proceso de establecimiento de equivalencias se completa en el plano textual. Corpas (2003: 219) identifica tres posibles dificultades que pueden detectarse en dicho plano. En primer lugar, que el traductor no identifique la UF como tal; en segundo lugar, que la reconozca, pero no sepa interpretarla correctamente en el contexto dado; y en tercer lugar, que el traductor reconozca e interprete correctamente la UF, pero no sepa ofrecer un equivalente adecuado de la misma.

El primer tipo de dificultad se refiere a los casos cuando el traductor no reconoce el carácter fraseológico de una construcción, por lo que la manipula como si de una metáfora se tratara. Podemos considerar que en tal caso estaríamos ante una laguna en la competencia lingǘstica del traductor. En el segundo tipo, cuando el traductor no consigue dotar a la UF de un significado adecuado dentro del contexto dado, creemos que podemos hablar de una descompensación en la competencia comunicativa de aquel. Y, finalmente, si, a pesar de cumplir los dos requisitos anteriores, el traductor no es capaz 
de ofrecer un equivalente válido de la UF en la lengua meta, estaríamos, obviamente, ante las insuficiencias en la competencia traductológica.

La lista de las dificultades de traducción que puedan encontrarse en el plano textual muestra que esta fase final del proceso traductológico en realidad aglutina todas las anteriores; o, mejor dicho, las deficiencias que en ella se manifiestan son arrastradas directamente de las fases anteriores.

Visto el panorama expuesto hasta ahora, parece que el proceso completo de la traducción de las UF puede representarse según aparece en el esquema 1:

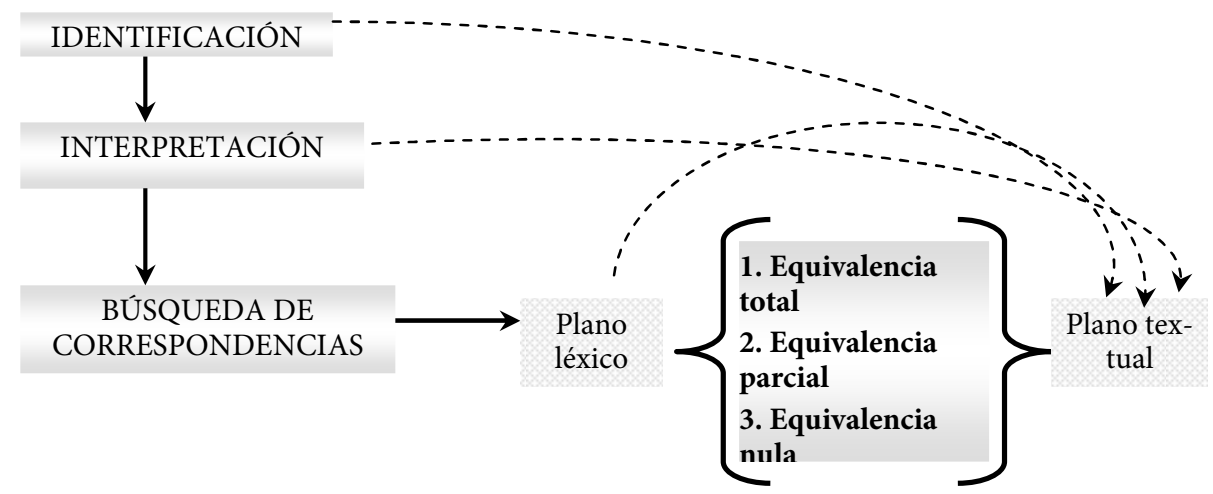

Esquema 1. El proceso de traducción de las UF

Las respectivas fases traductológicas se presentan de manera secuencial (flechas gruesas) y se culminan en el plano textual; asimismo, los problemas encontrados en cada una de las fases también pueden tener incidencias directas en dicho plano textual (flechas discontinuas).

\subsection{La traductología fraseológica desde la concepción funcional}

Acabamos de ver que la problemática equivalencial que se encuentra en el plano textual deriva directamente de las insuficiencias localizadas en las fases traductológicas anteriores. Pero la práctica muestra que incluso si se cumplen con rigor todas las etapas de traducción, ello no garantiza un resultado correcto en la fase final del nivel textual. Dicho de otro modo, incluso si el traductor ha sabido identificar correctamente la UF, ha sido capaz de interpretarla adecuadamente en su contexto y le ha proporcionado un equivalente en el plano léxico, tal equivalente no siempre resulta perfectamente ajustado al contexto meta (cfr. v.g. Corpas, 2003: 219-222). 
Semejante situación ha hecho a los estudiosos del tema postular la necesidad de una base de orientación práctica para el concepto de equivalencia fraseológica. En efecto, incluso los aparentes equivalentes totales con frecuencia no resultan tales, una vez analizadas sus circunstancias de uso, aspectos connotativos, sociolingüísticos, culturales, etc. En otras palabras, un enfoque adecuado de la fraseología interlingüística, en opinión de estos especialistas, debe plantearse desde la perspectiva de la función que realizan las UF en sus respectivas lenguas.

Como se observa, el enfoque propuesto responde al patrón teórico general de corte funcional que domina fundamentalmente en la traductología actual. Ello hace pensar que el objetivo de la traductología fraseológica funcional consiste en proporcionar una traducción de la UF original, con atención a todos los aspectos señalados, que se adecue al texto meta. Tal hecho conlleva la reformulación del sistema equivalencial expuesto hasta ahora, que se refunde en la noción de equivalencia fraseológica funcional. Según los promotores de esta visión, se trata de una noción que pretende aglutinar todo lo que está implicado en la comparación interlingüística de las UF, en tanto que cumplidoras de determinadas funciones de diversa índole (cfr. Dobrovol'skij, 1997; 1998; 2000; Mellado, 2000; Corpas, 2003: 254 y sigs., entre otros).

El establecimiento de equivalencia fraseológica funcional obedece a una serie de parámetros, que se agrupan en semánticos, morfosintácticos y pragmáticos?. La remodelación que sufre, a efectos de esta nueva perspectiva, la tricotomía de equivalencias que hemos presentado arriba da lugar a ciertas variaciones, más o menos importantes, dentro del marco fraseológico funcional general; aspectos estos que se evidencian en diversas clasificaciones propuestas a partir del enfoque funcional en aplicación, generalmente, a tipos concretos de UF. A continuación, y a modo de ejemplo, veremos una de tales propuestas, la de Mellado (2000).

\subsubsection{Enfoque funcional de la traducción de la fraseología locucional cinésica: Mellado} (2000)

Mellado (2000) realiza la aplicación de la tricotomía equivalencial tradicional, enfocada desde la perspectiva funcional, a los casos de "verbalización estereotipada de distintas realizaciones cinésicas de comunicación no verbal" (Mellado, 2000: 389). Según la

\footnotetext{
${ }^{9}$ En Corpas (2003: 254-263) se ofrece un completo resumen del contenido de cada parámetro comparativo, que puede servir de guía sobre una visión general del tema.
} 
autora, estas UF con elementos cinésicos presentan los siguientes casos de equivalencia en el par de lenguas alemán-español.

El primer tipo de equivalencia, la equivalencia funcional, se refiere a los casos en los que el binomio fraseológico alemán-español tiene el mismo significado fraseológico. Este tipo se subdivide, a su vez, en al menos ocho subtipos equivalenciales que exponemos brevemente a continuación (Mellado, 2000: 400-403):

- equivalencia plena (Mellado, 2000: 400):

Equivalencia en el significado literal, en el fraseológico, en la estructura morfosintáctica (actancial), y en el componente pragmático. Las diferencias tipológicas, propias de la estructura particular de cada lengua, no son relevantes.

- diferencias exclusivamente en la estructura actancial: recoge los casos de divergencia en la valencia sintáctica interna y externa;

- diferencias en la composición léxica, aunque el significado literal en conjunto es prácticamente el mismo: son, especialmente, casos cuando los componentes de las UF comparadas establecen relaciones metonímicas tipo parte-todo ${ }^{10}$;

- diferencias en el significado literal, aunque en el resto de los niveles son equivalentes: se trata de los casos cuando en cada una de las lenguas para un mismo concepto se utilizan imágenes cinésicas diferentes;

- falta de correspondencia en el componente pragmático: cuando las UF comparadas presentan diferencias en las condiciones de uso;

- falta de equivalencia en la realización del gesto en el nivel literal: las divergencias en esta ocasión se deben, sobre todo, a las particularidades interculturales en la realización de algún acto cinésico;

- casos en los que a una UF cinésica en una lengua le corresponde una UF no cinésica en otra lengua, por lo que tienen un significado literal distinto;

- casos en los que a una UF en una lengua le corresponde en otra lengua un lexema simple utilizado en sentido figurado muy próximo al significado fraseológico de la construcción de origen.

Como se observa en la clasificación propuesta por Mellado (2000), la autora presenta una considerable reformulación de la concepción equivalencial que hemos visto an-

\footnotetext{
${ }^{10}$ Un interesante tratamiento de este tipo de relaciones, así como de otras representadas en la propuesta de Mellado, se realiza en el marco del Análisis Semémico propuesto por Kopylenko y Popova, en el que este subtipo de equivalencia corresponde al segundo grado de idiomaticidad interlingüística. Para más detalle, se puede consultar Kopylenko y Popova (1978), Popova (1993), así como Timofeeva (2012: 168-173).
} 
tes. La noción de equivalencia funcional se contempla en relación con los diversos niveles sistémicos implicados en la realización de una determinada función discursiva por parte de la UF. No obstante, y pese a tal propósito, cabe anotar que las equivalencias presentadas se analizan aisladamente del discurso; es decir, en realidad su valor funcional se contempla como algo inherente a las propias UF, lo que no contempla, naturalmente, la posibilidad de que las UF puedan desarrollar en el discurso funciones que en principio no están grabadas en su "genética". Sin embargo, a nuestro juicio, son aspectos decisivos que hay que tener en cuenta en el proceso de traducción de las estructuras fraseológicas, pues su significación se completa en tanto que parte de un enunciado mayor, donde la influencia de diversos factores discursivos y contextuales tendrá, también, consecuencias traductológicas.

La clasificación de Mellado (2000) reformula, por otra parte, la noción de equivalencia parcial, que se define también en términos funcionales. Así, la autora distingue dos subtipos de equivalencia parcial (Mellado, 2000: 403-404):

- equivalencia parcial en las UF polisémicas: se habla de los casos cuando el "inventario" semémico que configura el significado de una UF polisémica no coincide en las dos lenguas comparadas;

- equivalencia parcial en función de la composición actancial de las UF comparadas: son casos cuando las variaciones puramente actanciales en la UF de una lengua obligan a buscar equivalentes distintos en la lengua meta.

Finalmente, dentro de la clasificación se incluyen los casos de falta de equivalencia fraseológica, cuando el significado convencionalizado ha de ser parafraseado; y el fenómeno de los falsos amigos fraseológicos, al que ya nos hemos referido anteriormente.

Como se desprende de la clasificación presentada, los dos tipos de equivalencia principales, el funcional y el parcial, no se excluyen, por lo que uno puede darse en conjunto con el otro. En realidad ello es posible porque en la concepción de Mellado (2000) parece que ambos tipos afectan a las UF en niveles distintos: la equivalencia funcional actúa más bien en el nivel de sintagma, mientras que la equivalencia parcial es de carácter paradigmático. Por este motivo, tal vez, cabe hablar simplemente de distintos grados de equivalencia funcional, tal y como la presenta Mellado, pues la concepción de equivalencia parcial contemplada en la clasificación de la autora no responde, en realidad, al patrón propiamente funcional.

En definitiva, la idea más importante que hemos pretendido mostrar hasta ahora se refiere a la toma de conciencia - por parte del acercamiento funcional a la fraseología interlingüística - sobre la diversidad de factores implicados en el acto traductológico de este tipo de unidades. Ello requiere una mayor indagación en el propio significado fra- 
seológico, con atención a informaciones de diversa índole que lo configuran. Por ello, la reformulación de la tricotomía equivalencial tradicional en términos de equivalencia fraseológica funcional se ofrece como una alternativa que se apega más a la práctica y a la realidad (cfr. Dobrovol'skij, 2000; así como Dobrovol'skij y Piirainen, 2005).

\subsection{Críticas a la traductología fraseológica funcional}

Pese a los buenos propósitos del enfoque funcional enunciados en el apartado anterior, el tratamiento interlingüístico de las UF desde dicha perspectiva revela, también, una serie de defectos que impiden aceptarlo incondicionalmente. A continuación exponemos nuestras razones para considerar el acercamiento funcional como incompleto y necesitado de un marco más amplio.

\subsubsection{Problemas derivados del enfoque clasificatorio: sobreespecificación y heterogeneidad de criterios}

El primer problema del enfoque descrito arriba lo observamos en el afán clasificatorio. En efecto, como sucede en otros casos, la traductología fraseológica pretende describir, a través de las tipologías, toda la gama de posibles fenómenos que puedan darse en la dura tarea de translación de las UF. Las descripciones que se presentan de las UF de un determinado tipo, como, por ejemplo, las de cierto campo semántico, no hacen más que detallar y aumentar el patrón clasificatorio general, con el supuesto objetivo de mejorarlo. En tal carrera por la perfección clasificatoria se sacrifica, con frecuencia, la naturaleza eminentemente individual de las UF.

La afirmación anterior no pretende suponer que las UF constituyen creaciones únicas y no sometibles a ningún tipo de sistematización. Creemos que la propia historia de la investigación fraseológica ha demostrado que podemos detectar una serie de patrones análogos, presentes seguramente en todas las lenguas, que posibilitan la construcción de una teoría comparativa general. No obstante, ello no significa que debemos obviar el carácter idiosincrásico de cada UF. Recordemos que estamos operando con unidades de denominación secundaria ${ }^{11}$, es decir, en principio, prescindibles para trasmitir mensajes lingüísticos ${ }^{12}$. Por ello, cabe pensar que su creación se debió a causas especiales, muy

\footnotetext{
${ }^{11}$ En Timofeeva (2008) exponemos con más detalle la secundariedad denominativa de las UF, donde ésta se presenta como un rasgo definitorio de pertenencia al acervo fraseológico.

${ }^{12}$ No debemos rasgarnos las vestiduras a causa de tal afirmación, ya que no significa, de ningún modo, que las UF realmente sean prescindibles. Más bien lo contrario, si atendemos a las perspectivas teóri-
} 
concretas, que se han ido enriqueciendo por los hablantes a lo largo de la vida de la UF. Tales causas originarias, verdaderas o no, persisten en la conciencia del hablante como un poso que asegura la unicidad de una UF, a la que se recurre, ciertamente, para trasmitir al mensaje un matiz más o menos relevante, pero también único. Es por lo que resulta un tanto contradictorio que un enfoque que centra su atención en la función que cumple la UF, pase por alto ese carácter único e individual de este tipo de estructuras.

Las consecuencias del "choque" entre el afán de clasificar y el carácter inherentemente individual de las UF se manifiestan, en nuestra opinión, en clasificaciones largas y minuciosas que no pretenden más que dar cuenta de toda la variedad equivalencial real. Se intenta mantener un equilibrio entre dicha variedad y los propósitos generalizadores que sustentan cualquier acercamiento teórico; pero lo que vemos es que a menudo se cae en el error de la sobreespecificación, cuando un determinado subgrupo clasificatorio apenas abarca unos cuantos casos reales.

Junto con el problema de la sobreespecificación, y relacionado con él, la concepción descriptivo-clasificatoria presentada manifiesta otra deficiencia remarcable. Si analizamos las variedades tipológicas que configuran la clasificación equivalencial, nos damos cuenta de su considerable heterogeneidad. Mientras que unas variedades se comparan con atención a su sintaxis, otras lo hacen en el nivel semántico, etc. Una parte de tal heterogeneidad, por tanto, se aborda, lógicamente, mediante los parámetros comparativos semánticos, sintácticos y pragmáticos que adopta la fraseología funcional. Pero la realidad es que, con frecuencia, las similitudes y las diferencias detectadas entre la UF original y la UF meta no se adscriben a un solo parámetro, bien porque son varios los que están implicados en la configuración de una equivalencia, bien porque dichos parámetros afectan en unos casos a toda la UF, y en otros solo a algunas de sus partes.

Ante tal situación cabe plantearse si lo que hay que clasificar o sistematizar de algún modo son las UF o, tal vez, otra cosa. Tal vez, lo que debemos intentar sistematizar es algo que caracteriza a las UF como tales. A nuestro juicio, debemos indagar en la naturaleza del significado fraseológico, para determinar qué tipos de información, sistematizable, lo configuran, y en qué grado se manifiestan. Quizá en ello consista la razón de la heterogeneidad clasificatoria a la que aludíamos antes, pues lo que sucede es que se miden con el mismo rasero los aspectos del significado fraseológico que ocupan distintas posiciones.

cas sobre la comunicación vigentes en la lingüística actual, que confirman que un significado fraseológico no es sustituible por el de un lexema de denominación primaria sin que ello ocasione pérdidas de significado importantes. 
Si nuestra hipótesis es cierta, cabe pensar en el significado fraseológico compuesto por una serie de bloques informativos, y que la información presente en dichos bloques se manifiesta en grados distintos. El conocimiento de las informaciones y de los grados de las mismas en cada UF forma parte de la competencia lingüística del traductor en la lengua del texto origen. Asimismo, el reflejo de tales aspectos es la tarea fundamental de los estudios descriptivos ${ }^{13}$ y de la fraseografía. No obstante, y en ello radica, a nuestro parecer, el segundo problema del enfoque funcional presentado, la consideración de todos estos aspectos no es, a todas luces, suficiente, para proporcionar una traducción de un texto que contiene la UF.

\subsubsection{Desatención al nivel del discurso}

Otro aspecto que revela la concepción funcional presentada se refiere a la completa desatención que muestra hacia el discurso. En efecto, resulta cuanto menos extraño que un enfoque que se basa en la función que desempeña la UF contemple dicha función solo en el nivel del significado convencionalizado. Los parámetros de comparación de índole semántica, sintáctica y pragmática son aplicados exclusivamente en ese nivel de significado, sin considerar su incidencia en el contexto discursivo más amplio.

La crítica anterior no debe interpretarse como la pretensión de desechar el procedimiento de análisis adoptado por la fraseología funcional. No estamos diciendo que sea incorrecto, más bien lo contrario. Compartimos totalmente la opinión que sostiene dicha corriente de que en el interior de una UF se dan cita los factores de todos los niveles sistémicos, y todos juntos organizan el significado de la UF. Pero también creemos que tales factores - semánticos, sintácticos y pragmáticos - marcan el enunciado mayor en el que aparece insertada la UF.

En efecto, no debemos olvidar que una UF funcionalmente es un lexema ${ }^{14}$, por lo que desarrolla sus funciones por completo en condiciones de un enunciado mayor. De ahí nuestro asombro por la desatención que recibe este aspecto en el enfoque funcional. Asimismo, si a estas alturas ya resulta unánime el reconocimiento de la complejidad del significado fraseológico, parece lógico que se plantee la cuestión sobre las consecuencias

\footnotetext{
${ }^{13}$ Adviértase que el planteamiento que estamos realizando supone que los estudios descriptivos deben ocuparse justamente de describir los casos fraseológicos concretos, sin el objetivo de clasificarlos.

${ }^{14}$ Naturalmente, se puede objetar que son lexemas funcionales solo UF con estructura sintagmática no enunciativa; sin embargo, creemos que no siempre es así, y que incluso determinadas UF enunciativas no dejan de ser lexemas funcionales en cuanto que necesitan de un discurso mayor para actualizar su significado (cfr. Dobrovol'skij, 2000; Baranov y Dobrovol'skij, 2000; Dobrovol'skij y Piirainen, 2005).
} 
de dicha complejidad en el enunciado general que acoge al fraseologismo. Y es que se piensa erróneamente que una UF se integra en el enunciado con su significado, aunque complejo, pero bastante estático, que no varía sustancialmente de un contexto a otro. No obstante, no sucede así: los valores que integran el significado de una UF se presentan como potenciales, y en el discurso manifiestan un desarrollo desigual en función de las circunstancias contextuales. Si la relación entre tales valores potenciales y su manifestación en el discurso puede sistematizarse de algún modo, significa que hasta cierto punto pueden ser predecibles. Y ello, naturalmente, puede tener interesantes implicaciones de cara al tratamiento interlingüístico de las UF.

En definitiva, y a modo de una conclusión provisional, podemos decir que el enfoque funcional necesita ser completado en lo que al comportamiento discursivo de las UF se refiere. En otras palabras, dicho enfoque a primera vista parece adecuado como un acercamiento teórico al significado fraseológico sui generis, esto es, el significado convencionalizado. Sin embargo, en lo que se refiere a la UF como parte de un enunciado mayor, es una dimensión que la perspectiva funcional, a nuestro juicio, no está capacitada para abarcar. Para tal dimensión hay que buscar concepciones más amplias que se refieran a la comunicación en términos más generales; y ello supondrá, naturalmente, cambios sustanciales en toda la problemática traductológica de las UF.

\section{Nuevas vías de investigación: la aplicación de las teorías pragmáticas}

En la línea que analizábamos la problemática de la traducción de los fraseologismos en el apartado anterior, parece evidente que un enfoque de índole pragmática se presenta como el más adecuado. Solo un acercamiento pragmático puede revelar las particularidades del comportamiento fraseológico dentro de un enunciado. Pero además, y dada la naturaleza enunciativa de la UF, cabe pensar que las herramientas pragmáticas también pueden resultar de utilidad en el nivel de significado convencionalizado.

En este sentido, en la ciencia traductológica se abre una nueva vía de investigación, basada en la aplicación de los supuestos teóricos de determinadas propuestas pragmáticas al estudio de la traducción. A continuación revisaremos las líneas maestras de una de tales propuestas innovadoras, la de E.-A. Gutt (1991; 2000), que pretende abordar la problemática de la traducción desde la perspectiva de la Teoría de la Relevancia de Sperber y Wilson ([1986] 1994).

\subsection{El enfoque comunicativo vs el enfoque 'input-output'}

Como hemos visto en el apartado 2, tanto las propuestas teóricas tradicionales, como la visión funcional vigente en la traductología actual se amoldan, básicamente, a un 
mismo patrón que Gutt (2000: 204-205) llama el modelo traductológico 'input-output'. Los parámetros utilizados por dicho patrón son de índole puramente comparativa, y desatienden, según hemos visto en el caso de las UF, numerosos aspectos referentes a la dimensión comunicativa de la traducción.

El giro radical que propone Gutt como fundamento para su concepción teórica consiste en reconsiderar la traducción como parte de la comunicación. En efecto, como señala el autor (cfr. Gutt, 2000: 22; 205-206), los recelos que han manifestado los enfoques anteriores hacia tal visión se relacionan con un modelo concreto de comunicación que dominaba la ciencia lingüística desde el estructuralismo. Se trata de la comunicación entendida en términos de decodificación; esto es, que la comunicación lingüística consiste en la tarea de codificar el mensaje por parte del emisor, para que ése sea decodificado posteriormente por el receptor.

No obstante, sabemos que dicho modelo comunicativo ha quedado obsoleto a la luz de las investigaciones más actuales; investigaciones que han demostrado que el proceso comunicativo se completa por un más o menos sofisticado entramado inferencial, y tal parcela inferencial constituye la esencia de toda interrelación humana. Gutt parte de dichas premisas para demostrar que la traducción puede y debe considerarse y estudiarse desde los presupuestos comunicativos, lo que implica reformulaciones y ajustes importantes respecto, fundamentalmente, a la teoría funcional de traducción.

Gutt parte en su argumentación de dos puntos que constituyen, en su opinión, los principales aspectos problemáticos del planteamiento traductológico de corte funcional vigente: la construcción de la teoría en términos descriptivo-clasificatorios, y la elección del dominio de la disciplina. Ambos problemas están imbricados, por lo que articulan la propuesta de Gutt de manera integradora. Así, el hecho de reconsiderar la naturaleza comunicativa del proceso de traducción tiene implicaciones en la elección del dominio traductológico, lo que, a su vez, muestra la inadecuación del enfoque descriptivoclasificatorio.

De esta forma, la primera medida que se adopta consiste en enfocar el proceso de traducción desde el punto de vista de la competencia, más que desde el de la conducta comunicativa (cfr. Gutt, 2000: 21; 205). Este hecho deriva en que son las capacidades mentales de los seres humanos para comunicarse las que se ponen en el punto de mira. No es que los textos de origen y de meta pierdan su importancia, sino que éstos dejan de ser el eje que articula la concepción del proceso traductológico. Se trata de indagar en la naturaleza mental, en la facultad cognitiva humana para comunicarse, o, en palabras de Gutt (2000: 206): 
The aim of CORT [competence-oriented research of translation] is to understand and explicate the mental faculties that enable human beigns to traslate in the sense of expressing in one language what has been expressed in another. The idea is that once these faculties are understood, it is possible to understand not only the relation between input and output, but also, and perhaps more importantly, the communicative effects they have on the audience.

Tal concepción presenta como consecuencia la afirmación de que en el nivel psicológico el proceso de traducción no es esencialmente distinto al de cualquier proceso comunicativo inferencial. Gutt sostiene que la Teoría de la Relevancia, postulada por Sperber y Wilson, provee bases teóricas necesarias para llegar a tal conclusión.

Para ello, el autor estudia distintos fenómenos de actividad interlingüística analizados generalmente bajo el paraguas de traducción. Así, por ejemplo, se estudian determinados casos de traducciones que ponen en entredicho la noción de equivalencia funcional desarrollada por el enfoque funcional (Gutt, 2000: cap. 3) ${ }^{15}$. Se trata de ejemplos de traducciones de textos de orden publicitario, instrucciones de uso, guías turísticas, etc., en las que, evidentemente, el resultado de la traducción ha de perseguir la consecución de una determinada función en la lengua meta. Sin embargo, sostiene Gutt, el análisis comparativo de los textos de este tipo revela una particularidad importante, pues presentan un considerable nivel de divergencia en algunos aspectos que impiden tratarlos como traducciones estrictamente hablando de cierto texto de origen. En otras palabras, las supuestas traducciones a varias lenguas dentro de un folleto turístico, por poner un ejemplo, actúan de manera bastante independiente, por lo que en ocasiones resulta incluso imposible determinar con certeza el texto en qué lengua sirve de punto de partida inicial.

Ante tal situación, y frente a la explicación ya clásica en términos de equivalencia funcional como el objetivo primordial de toda traducción, Gutt ofrece una visión alternativa de dicho hecho. Para ello, parte de la afirmación de que en los casos estudiados la preservación de las funciones no asegura, de hecho, que la traducción sea funcionalmente equivalente (Gutt, 2000: 51) ${ }^{16}$. De esta forma, Gutt se adhiere, de algún modo, a la

\footnotetext{
${ }^{15}$ Cabe recordar que para la traductología actual la noción de equivalencia funcional se contempla dentro de la teoría general de escopos, o de finalidad que debe cumplir el texto traducido respecto a su público receptor. En este sentido, se puede consultar Reiss y Vermeer ([1984] 1997) o Hurtado Albir ([2001] 2007).

${ }^{16}$ Gutt (2000: 50-51) señala, respecto a las traducciones de los folletos turísticos, que la búsqueda de equivalencia funcional suscita al menos dos preguntas relacionadas con el cumplimiento de la función de atraer a los turistas a un determinado lugar, exaltando su belleza e interés. En primer lugar, ¿cómo puede determinar el traductor si su traducción es funcionalmente equivalente respecto al original en lo
} 
idea de que las funciones textuales no deben tratase como constantes que han de preservarse a toda costa en el texto traducido, sino como variables a la par con otras presentes en el texto de origen (cfr. Hönig y Kußmaul, 1982 apud Gutt, 2000). Sin embargo, lo que sí se preserva en los textos de carácter turístico, publicitario y otros por el estilo es la intención de atraer la máxima atención de los potenciales clientes. Dicho de un modo más gráfico, el que publica un folleto turístico está mucho más interesado en que la versión en otras lenguas sea lo más efectiva posible para atraer a los turistas, que en hasta qué punto dicha versión corresponde al texto original en términos de una noción teórica como equivalencia. Y lo mismo es aplicable a los receptores de tales textos, pues lo que buscan éstos es recibir información relevante para ellos y para sus planes (Gutt, 2000: 57).

De esta forma, la traducción no busca asemejarse al texto original, por lo que este se presenta como algo puramente incidental. En opinión de Gutt, tal tipo de 'traducción' tiene cabida en el marco teórico de la Teoría de la Relevancia, concretamente en la dimensión descriptiva del uso del lenguaje $\mathrm{e}^{17}$, lo que supone que el tratamiento de los casos descritos no necesita ninguna teoría traductológica específica.

Naturalmente, no todos los casos de traducción son como los analizados arriba. Hay otros en los que la traslación del mensaje del texto de origen se hace primordial y no omisible. Sucede así, por ejemplo, con la traducción de los textos artístico-literarios, en los que el objetivo de la traducción consiste en comunicar el significado del original lo más preciso, veraz y claramente posible para los lectores de la traducción (Gutt, 2000: 69). Este tipo de traducciones, a primera vista, parecen responder al patrón interpretativo del uso del lenguaje en el marco de la Teoría de la Relevancia.

que a los efectos halagadores se refiere? ¿debe comprobar si su traducción conserva el efecto buscado en las partes concretas del texto; o comparar la correlación numérica de los enunciados halagadores en el texto origen y en el meta; o contrastar una especie de efecto halagador total como suma de todos los enunciados halagadores a lo largo del texto? Y en segundo lugar, ¿qué sucede si la exaltación y la pretensión excesivas no están bien aceptadas en la cultura meta? La reflexión en torno a estas preguntas le lleva a Gutt a realizar la afirmación citada.

${ }^{17}$ En su teoría, Sperber y Wilson presentan una concepción del uso del lenguaje articulada en dos dimensiones, la descriptiva y la interpretativa. Tal visión pretende acomodar no solo las interpretaciones literales, sino también aquellos casos en los que el concepto que el hablante intenta comunicar, de alguna forma, parte del concepto expresado explícitamente en el enunciado. Así, mientras que la descripción constituye una representación fiel de un determinado estado de cosas, la interpretación es una representación de otra representación proposicional en virtud del parecido de algún tipo entre ambas proposiciones. Para una presentación más detallada de los presupuestos de la Teoría de la Relevancia, vid. Sperber y Wilson ([1986] 1994), Wilson y Sperber (2004). 
No obstante, una indagación más profunda en el tema muestra que las cosas no son tan sencillas. La visión tradicional defiende que la traslación del mensaje del original debe ser completa y veraz. Ello implica el respeto no solo de los aspectos lingüísticos del texto origen, sino también de los estilísticos, psicológicos y otros. Dicho de otro modo, el objetivo es que el receptor del texto traducido responda al mensaje en su lengua sustancialmente de la misma forma que los receptores del texto origen ${ }^{18}$.

En realidad, este propósito traductológico no es nada nuevo, ni tampoco nada sencillo de poner en práctica. Presentado por sus defensores como una concepción teórica general de la traducción, dicho propósito debería poder ofrecer una explicación coherente a todas las situaciones comunicativas posibles que se pueden dar en el proceso de traducción. Mientras tanto, según sostiene Gutt (2000: 76 y sigs.), las propuestas teóricas basadas en la transmisión precisa y veraz del mensaje del texto origen dan cuenta solo de lo que el autor llama situaciones comunicativas primarias (primary communication situations), es decir, aquellas en las que las condiciones del texto o enunciado producido aparecen combinadas con las asunciones contextuales correspondientes. No obstante, las propuestas traductológicas citadas no son capaces de explicar las situaciones comunicativas secundarias (secondary communication situations), o sea, aquellas en las que la interpretación del texto parte de asunciones contextuales erróneas, o no intentadas por el emisor, lo que en muchos casos lleva, lógicamente, a las interpretaciones incorrectas o fallidas.

Cuando una traducción aparece involucrada en una situación comunicativa secundaria, naturalmente, se ve afectada por las interpretaciones incorrectas. Ello explica fallos o aparentes incongruencias que podemos encontrar en las traducciones de algunos textos antiguos o de culto, así como en traducciones modernas cuando el traductor no ha sabido interpretar correctamente las condiciones contextuales implicadas en el mensaje del texto original. Las concepciones teóricas que insisten en la veracidad y precisión del mensaje traducido respecto al original no pueden explicar tales casos en términos que no sean de fallo o de incumplimiento. Sin embargo, y dado el carácter corriente de las situaciones comunicativas secundarias, Gutt sostiene que tal explicación resulta fuera de lugar, pues una teoría general debe ser capaz de dar cuenta de todas las situaciones posibles, tanto las menos como las más problemáticas, o en sus propias palabras (Gutt, 2000: 98), "what we are interested in here is not a theory that will work well only in the less problematic situations, but an account of translation in general".

\footnotetext{
${ }^{18}$ En esta idea se fundamenta la noción de equivalencia dinámica de Nida y Taber (1969).
} 
La aplicación de los supuestos teóricos de corte relevantista a la idea de la transmisión fiel y veraz del mensaje del texto original tampoco da resultados satisfactorios. Como señala Gutt (2000: 99)

Thus to say that a translation should communicate the same interpretation as the intended in the original means that it should convey to the receptors all and only those explicatures and implicatures that the original was intended to convey (cursiva en el original).

La práctica, sin embargo, demuestra que ello no siempre es posible, pues las circunstancias contextuales de la lengua origen y de la meta no siempre pueden coincidir. Dicho de otro modo, y dada la dependencia directa de las nociones de explicatura e implicatura del contexto, éste puede modificar una de ellas, por lo que la traslación del mensaje dejaría de ser fiel y veraz.

Por lo tanto, concluye Gutt (2000: 103-104), parece un intento fallido crear una teoría general de la traducción que contemple dicho proceso en términos de translación al público receptor en la lengua meta del mismo mensaje que se llevó al público del original. Tal objetivo se consigue en las llamadas situaciones comunicativas primarias; pero, sin embargo, su consecución se convierte en más difícil cuantas más diferencias muestren las circunstancias contextuales del público receptor y del público original, esto es, en las situaciones comunicativas secundarias.

Ante tal situación, Gutt (2000: cap. V) plantea la posibilidad de considerar el proceso de traducción como un uso interpretativo a través de las fronteras de las lenguas, esto es, un uso interpretativo interlingüístico. Precisamente tal carácter interlingüístico permite distinguir la traducción de otros ejemplos de uso interpretativo contemplados por la Teoría de la Relevancia.

Dicha perspectiva supone que la traducción se presenta como el texto en la lengua meta que interpretativamente se asemeja al original. Ello se basa en la siguiente cadena de reflexión: los enunciados trasmiten las interpretaciones, pero éstas dependen de las consideraciones de relevancia, y la relevancia, a su vez, es dependiente del contexto. Consecuentemente, la interpretación de los enunciados también es contextualmente dependiente, y la semejanza entre dos enunciados debe ser, asimismo, contextualmente dependiente. Dicho de otro modo, dos enunciados semejantes en un contexto pueden no serlo en contextos diferentes (cfr. Gutt, 2000: 44-46). Esta afirmación explicaría las situaciones comunicativas secundarias a las que nos hemos referido antes.

Por lo tanto, mientras que las situaciones comunicativas primarias se desarrollan, por así decirlo, en el mismo contexto (aunque en distintas lenguas), las situaciones comunicativas secundarias lo hacen en contextos distintos. Es por ello, por lo que el tra- 
tamiento de estas últimas debe subordinarse a un fin más general, como, en este caso, el del cumplimiento del Principio de Relevancia que debe respetar las circunstancias contextuales del público receptor.

De esta forma, Gutt afirma encontrar en el enfoque de la traducción como uso interpretativo interlingüístico la clave para solucionar el eterno problema traductológico del concepto de fidelidad o equivalencia. Su propuesta, insiste, tiene un carácter generalizado y, además, abarca tanto los aspectos textuales como contextuales. El propio Gutt (2000: 127-128) lo expresa así:

It [concept of faithfulness] is generally aplicable in that it involves only notions believed to be part of general human psycology - the principle of relevante and the ability to engage in interpretive use. It is text-specific in that interpretive use will link the communicative intention of the translator to the intended interpretation of the original text. It is context-specific in that the search for consistency with the principle of relevance always brings in the particular cognitive environment of the audience addressed.

Además, subraya el lingüista, la construcción de todo el anclaje teórico ha sido posible sin la necesidad de recurrir a los recursos clasificatorios de cualquier tipo. Por otra parte, la propuesta, en opinión de su autor, aclara el problema de la selección del dominio de la traductología. En opinión de Gutt (2000: 128), éste debe excluir los usos interlingüísticos descriptivos expuestos más arriba, así como casos de usos interpretativos no interlingüísticos.

\subsection{Hacia la reformulación de la traductología fraseológica}

Pese a no compartir todo el entusiasmo que muestra Gutt respecto a la aplicabilidad de los presupuestos relevantistas a la problemática de la traducción, debemos reconocer una serie de aspectos importantes que, en nuestra opinión, abren una nueva vía investigadora en la traductología moderna.

El proceso de traducción se contempla en la concepción de Gutt como parte del proceso general de comunicación, con la única particularidad de que en aquél están implicadas al menos dos lenguas distintas. Tal afirmación subraya la necesidad de analizar la traducción en el marco de una teoría general de la comunicación, con las herramientas que proporciona el mismo, como son los marcos de las teorías pragmáticas actuales.

La propuesta de Gutt, asimismo, pone de manifiesto la importancia del contexto para la traducción, concretamente cómo éste determina la interpretación definitiva de un enunciado. 
Como el propio Gutt (2000: passim) insiste, su propuesta teórica no pretende mostrar cómo deben analizarse y solucionarse los diversos problemas a los que se enfrenta la traducción de fenómenos concretos, ni tampoco dar reglas ni recetas ${ }^{19}$. La concepción de Gutt es de carácter explicativo, pues trata de entender y de indagar en las causas del proceso traductológico, así como en los mecanismos comunicativos que lo sustentan. Pese a tal propósito, el lingüista sostiene que su teoría presenta cierto carácter predictivo, pues permite predicciones empíricas respecto al posible éxito o fallo de efectos traductológicos (cfr. Gutt: 2000: 237).

En definitiva, al margen de compartir o no las reflexiones del autor, lo que resulta importante es que Gutt inaugura una nueva etapa, en la que la traductología pretende situarse en la vanguardia de los estudios de corte pragmático. Este giro teórico se presenta de especial importancia para la traducción de las UF, pues ésta requiere un enfoque pragmático que deriva de la propia naturaleza del significado fraseológico.

Según hemos podido observar a lo largo de los apartados correspondientes, la fraseología comparada actual de corte funcional va pisando fuerte y se presenta como una visión innovadora del viejo problema de la traducción de los fraseologismos. No obstante, como hemos visto, el enfoque funcional desatiende los aspectos referentes al comportamiento de las UF dentro de un enunciado mayor, concretamente, no provee mecanismos para dar cuenta de las relaciones que establecen las particularidades del significado fraseológico convencionalizado con las circunstancias de un enunciado mayor que lo alberga. El análisis de tales mecanismos, a nuestro juicio, resulta decisivo para diseñar un modelo coherente del tratamiento interlingüístico de las UF, que es planteable solo desde la perspectiva pragmática. Dicho de un modo más gráfico, creemos que un acercamiento interlingüístico al lenguaje fraseológico debe contemplar no solo el significado fraseológico convencionalizado de manera aislada, sino las consecuencias del mismo en el discurso. El proceso de traslación de un enunciado que contiene una UF, por tanto, debe basarse en dicha doble dimensión, según reflejamos, de manera general, en el esquema 2 :

\footnotetext{
${ }^{19}$ El hecho de no encontrar en el libro soluciones prácticas a problemas traductológicos concretos le valió a Gutt una serie de críticas, como aparece reflejado en el "Postscript" a la edición de 2000.
} 


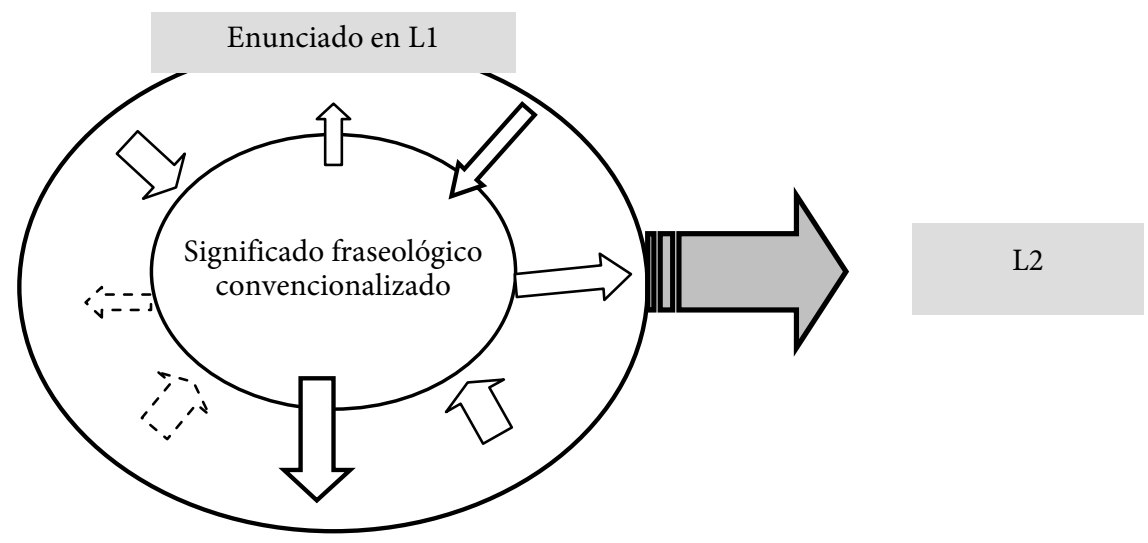

Esquema 2. La traducción fraseológca

Este esquema presenta al significado fraseológico convencionalizado dentro de un enunciado, ejerciendo influencias de diversa importancia en el mismo (flechas de distinto grosor), así como experimentando ajustes y arreglos, también de diverso grado, en función de las circunstancias contextuales concretas del enunciado en cuestión. Todo este entramado de relaciones configura, a nuestro juicio, la totalidad del significado fraseológico, por lo que debe quedar reflejado, de algún modo, en el resultado de la traducción. Asimismo, creemos que tales relaciones son sistematizables e inventariables en gran medida, por lo que adquieren cierto valor predictivo.

En conclusión, la primera tarea a la que se ha de enfrentar la traductología fraseológica actual consiste en la reformulación de su objeto, a saber, el significado fraseológico. En nuestra opinión, un modelo coherente de translación fraseológica ha de partir de la concepción de las UF en dos dimensiones, la de su significado convencionalizado y la de su actuación en el enunciado. Nuestra hipótesis es que muchas conclusiones a las que ha llegado el enfoque funcional se presentan operativas para la primera dimensión, aunque en algunos aspectos necesiten ser completadas y reformuladas. Las teorías pragmáticas actuales nos proporcionan, a su vez, herramientas complementarias tanto para el análisis del significado fraseológico en la primera, como en la segunda dimensión. Aquí solo hemos esbozado las vías de análisis que han de ser reforzadas con investigaciones más amplias y detalladas. 


\section{Conclusiones}

El somero recorrido por la problemática de la traducción de las UF realizado en este trabajo pone de manifiesto la necesidad de una profunda reflexión teórica en este ámbito. Como hemos podido comprobar, la noción de equivalencia fraseológica con la que operan los enfoques más tradicionales se ha visto superada por no ofrecer una explicación coherente de las decisiones traductológicas adoptadas en cada caso. En efecto, el cumplimiento de todas y cada una de las fases requeridas en el proceso de traducción no asegura que el equivalente fraseológico elegido sea contextualmente válido en la lengua meta. Como respuesta a este tipo de problemas, los enfoques funcionales buscan una solución más práctica centrada en la función que desempeña la UF en la lengua de origen. Tal planteamiento se fundamenta en un importante número de estudios descriptivos, lo cual provee, según sus defensores, la necesaria base empírica de las clasificaciones propuestas. No obstante, hemos visto que la visión funcionalista de la problemática de la traducción de los fraseologismos adolece de cierta sobreespecificación, derivada del afán de dar cabida a todos los posibles fenómenos que podemos encontrar en este ámbito. Ello provoca que determinadas categorías ilustran situaciones muy puntuales y poco representativas que no hacen más que abultar las clasificaciones correspondientes. Asimismo, pese a abogar por la importancia de la función de las UF, los enfoques presentados desatienden el nivel discursivo, nivel en el que las UF completan su función significativa en tanto que lexemas funcionales de estructura compleja.

Todas estas reflexiones nos llevan a afirmar la necesidad de adoptar un nuevo marco teórico, tanto en la traductología en general como en la fraseológica en particular. Dicho marco recurriría a herramientas de índole pragmática con el fin de ofrecer la visión global del hecho lingüístico objeto de traducción, con atención a todos los niveles de su configuración. Aplicando este razonamiento a la traducción de las UF, creemos que el nuevo planteamiento ha de partir de la reformulación de la significación fraseológica, cuyo estudio, a nuestro juicio, se ha de articular en dos niveles, el de significación convencionalizada y el de discurso. Un modelo coherente y sistematizado de tales aspectos tendría indudables consecuencias para la traducción de los fraseologismos.

Recibido: $19-X-2011$

Aceptado: 11-I-2012

\section{Referencias bibliográficas}

Almela, R., E. Ramón Trives y G. Wotjak (eds.) (2005): Fraseología contrastiva. Con ejemplos tomados del alemán, español, francés e italiano. Murcia, Universidad. 
Baranov, A. y D. Dobrovol'skij (1998): "Vnutrenniaja forma idiom i problema tolkovanija”, Izvestija RAN, serija literatury i jazyka 1 (tom 57), págs. 36-44.

Baranov, A. y D. Dobrovol'skij (2000): "Rechevyje formuly v dialogue“, Trudy Mezhdunarodnogo seminara Dialog-2000 (http://www.dialog21.ru/materials/archive.asp?id=6250\&y=2000\&vol=6077\#_ftnref1 ).

Corpas Pastor, G. (2003): Diez años de investigación en fraseología: análisis sintácticosemánticos, contrastivos y traductológicos. Madrid. Frankfurt am Main, Iberoamericana, Vervuert.

Corpas Pastor, G. (ed.) (2000): Las lenguas de Europa: estudios de fraseología, fraseografía y traducción. Granada, Comares.

Dobrovol'skij, D. (1996): “Obraznaja sostavljajuschaja v semantike idiom”, Voprosy jazykoznanija 1, págs. 71-93.

Dobrovol'skij, D. (1997): "Natsional'no-kulturnaja specifika vo fraseologuii (I)”, Voprosy jazykoznanija 6, págs. 37-48.

Dobrovol'skij, D. (1998): “Natsional'no-kulturnaja specifika vo fraseologuii (II)”, Voprosy jazykoznanija 6, págs. 48-57.

Dobrovol'skij, D. (2000): "Idioms in contrast: a functional view", en Corpas Pastor, G. (ed.): Las lenguas de Europa: estudios de fraseología, fraseografía y traducción. Granada, Comares, págs. 367-388.

Dobrovol'skij, D. (en prensa): “Sopostavitel'naja fraseologuija: mezhjazykovyje ekvivalenty i problemy perevoda idiom”, Russkij jazyk v nauchnom osveschenii, 22.

Dobrovol'skij, D. y A. Baranov (2000): "Fraseologuija“, Entsiklopedija Krugosvet (www.krugosvet.ru.).

Dobrovol'skij, D. y E. Piirainen (2005): Figurative language: cross-cultural and crosslinguistic perspectives. Amsterdam, Elsevier.

González Royo, C. y P. Mogorrón Huerta (eds.) (2008): Estudios y análisis de fraseología contrastiva: Lexicografía y Traducción. Alicante, Universidad.

Gutt, E.-A. (1991): Translation and Relevance. Cognition and Context. Manchester, Boston, St. Jerome Publishing.

Gutt, E.-A. (2000): Translation and Relevance. Cognition and Context (2a ed. revisada), Manchester, Boston, St. Jerome Publishing.

Hurtado Albir, A. ([2001] 2007): Traducción y Traductología. Introducción a la Traductología. Madrid, Cátedra.

Larreta Zulategui, J. P. (2001): Fraseología contrastiva del alemán y el español. Teoría y práctica a partir de un corpus bilingüe de somatismos. Frankfurt am Main, Peter Lang.

López Roig, C. (2002): Aspectos de fraseología contrastiva (alemán y español en el sistema y en el texto). Frankfurt am Main, Peter Lang. 
Le Poder, M.-E. D. (2006): "Discurso y traducción”, Actas del I Congreso Internacional de Análisis del Discurso: lengua, cultura, valores. Madrid, Arco Libros, págs. 19751980.

Mellado Blanco, C. (2000): "Formas estereotipadas de realización no verbal en alemán y español: los cinegramas desde un enfoque contrastivo-histórico", en Corpas Pastor, G. (ed.): Las lenguas de Europa: estudios de fraseología, fraseografía y traducción. Granada, Comares, págs. 389-410.

Nida E. A. y Ch. Taber ([1969] 1982): La traducción: teoría y práctica. Madrid, Cristiandad.

Nord, Ch. ([1988] 1991): Text analysis in translation: theory, methodology and didactic application of a model for translation-oriented text analysis. Amsterdam, Rodopi.

Nord, Ch. (1997): Translating as a purposeful activity: functionalist approaches explained. Manchester, Boston, St. Jerome Publishing.

Quiroga Murguía, P. (2006): "Discurso literario y traducción: la fraseología contrastiva italiana y española”, Actas del I Congreso Internacional de Análisis del Discurso: lengua, cultura, valores. Madrid, Arco Libros, págs. 2025-2036.

Raihshtein, A. D. (1980): Sopostavitel'nyj analiz nemetskoj i russkoj fraseologuii. Moskva, Vysshaja shkola.

Reiss, K. y H. J. Vermeer ([1984] 1997): Fundamentos para una teoría funcional de la traducción. Madrid, Akal.

Retsker, Y. (1950): “O zakonomernykh sootvetstvijakh pri perevod'e na rodnoj jazyk", en Teorija i metodika uchebnogo perevoda. Moskva, Izd. Akademii Pedagoguicheskij Nauk RSFSR.

Santoyo, J.C. y R. Rabadán (1991): "Basic Spanish Terminology for Translation Studies: a Proposal”, META 36, págs. 318-322.

Solodukho, E. M. (1977): Voprosy sopostavitel'nogo izuchenija zaimstvovannoj fraseologuii. Kazan', KGU.

Sperber, D. y D. Wilson ([1986] 1994): La Relevancia. Comunicación y procesos cognitivos. Madrid, Visor.

Timofeeva (2007): "Sobre la traducción de la fraseología. Un enfoque pragmático", Interlingüística, 17, págs. 1029-1038.

Timofeeva, L. (2008): "Los principios definitorios de las unidades fraseológicas: nuevos enfoques para viejos problemas”, ELUA, 22, págs. 243-261.

Timofeeva, L. (2009a): "Las unidades fraseológicas", en Ruiz Gurillo L. y X. Padilla (eds.): Dime cómo ironizas y te diré quién eres: una aproximación pragmática a la ironía. Frankfurt am Main, Peter Lang, págs. 193-217.

Timofeeva, L. (2009b): "La desautomatización fraseológica: un recurso para crear y divertir”, en Jiménez Ruiz, J. L. y L. Timofeeva (eds.): Estudios de Lingüística: Inves- 
tigaciones lingüísticas del siglo XXI, págs. 249-271.

Timofeeva, L. (2012): El significado fraseológico. En torno a un modelo explicativo y aplicado. Madrid, Ediciones Liceus.

Timofeeva, L. y L. Ruiz Gurillo (2008): "La ironía en locuciones nominales del español y del ruso". En González Rey, M. I. (ed.): A Multilingual Focus on Contrastive Phraseology and Techniques for Translation. Hamburg, Verlag Dr. Kovac, págs. 247-270.

Wilson D. y D. Sperber (2004): "La Teoría de la Relevancia", Revista de Investigación Lingüística 7, págs. 233-282. 